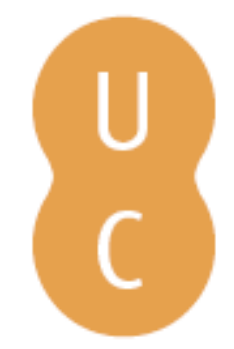

\title{
pommalina
}

\section{Short term forecasting of large scale wind-driven wildfires using thermal imaging and inverse modelling techniques}

Autor(es): $\quad$ Rios, Oriol; Pastor, Elsa; Tarragó, Diana; Rein, Guillermo; Planas, Eulàlia

Publicado por: Imprensa da Universidade de Coimbra

URL

persistente: URI:http://hdl.handle.net/10316.2/34282

DOI: $\quad$ DOI:http://dx.doi.org/10.14195/978-989-26-0884-6_103

Accessed : $\quad$ 26-Apr-2023 12:56:40

A navegação consulta e descarregamento dos títulos inseridos nas Bibliotecas Digitais UC Digitalis, UC Pombalina e UC Impactum, pressupõem a aceitação plena e sem reservas dos Termos e Condições de Uso destas Bibliotecas Digitais, disponíveis em https://digitalis.uc.pt/pt-pt/termos.

Conforme exposto nos referidos Termos e Condições de Uso, o descarregamento de títulos de acesso restrito requer uma licença válida de autorização devendo o utilizador aceder ao(s) documento(s) a partir de um endereço de IP da instituição detentora da supramencionada licença.

Ao utilizador é apenas permitido o descarregamento para uso pessoal, pelo que o emprego do(s) título(s) descarregado(s) para outro fim, designadamente comercial, carece de autorização do respetivo autor ou editor da obra.

Na medida em que todas as obras da UC Digitalis se encontram protegidas pelo Código do Direito de Autor e Direitos Conexos e demais legislação aplicável, toda a cópia, parcial ou total, deste documento, nos casos em que é legalmente admitida, deverá conter ou fazer-se acompanhar por este aviso.

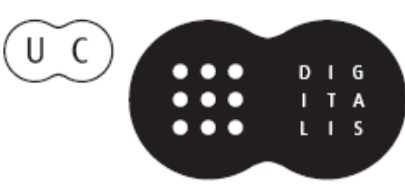




\section{ADVANCES IN}

Forest Fire

\section{RESEARCH}

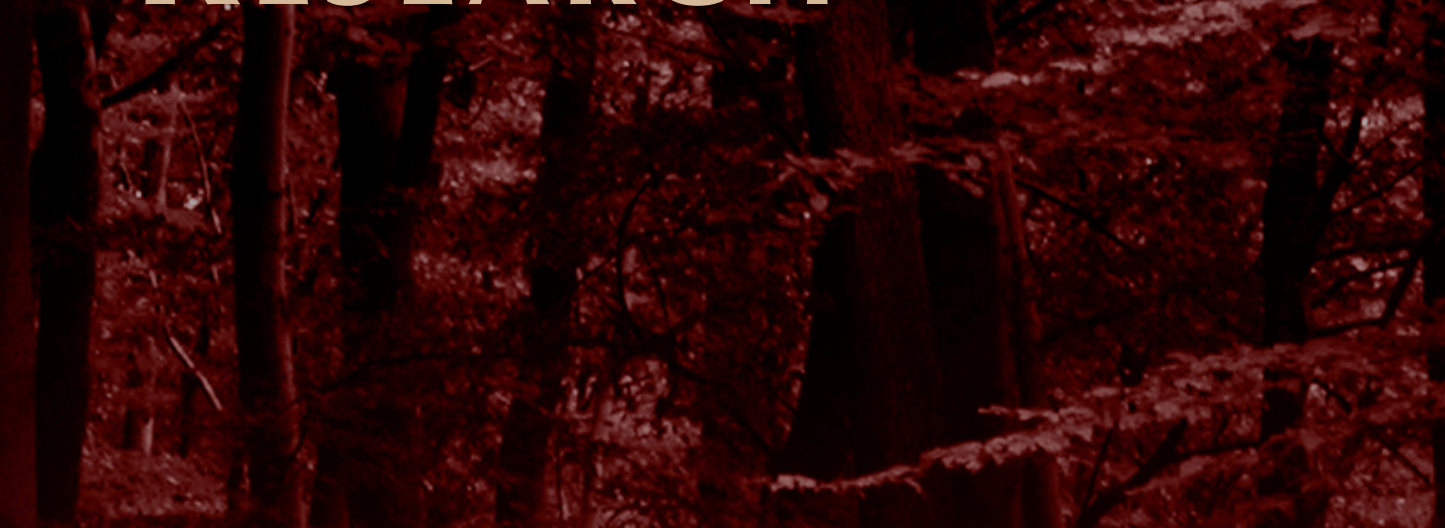

\section{DOMINGOS XAVIER VIEGAS}

\section{EDITOR}




\title{
Short term forecasting of large scale wind-driven wildfires using thermal imaging and inverse modelling techniques
}

\author{
Oriol Rios ${ }^{\mathrm{a}}$, Elsa Pastor ${ }^{\mathrm{a}}$, Diana Tarragóa ${ }^{\mathrm{a}}$, Guillermo Rein $^{\mathrm{b}}$, Eulàlia Planas ${ }^{\mathrm{a}}$ \\ ${ }^{a}$ Department of Chemical Engineering, Centre for Technological Risk Studies, Universitat \\ Politècnica de Catalunya-BarcelonaTech, Diagonal 647, E-08028 Barcelona, Catalonia, Spain. \\ oriol.rios@upc.edu, diana.tarrago@upc.edu, elsa.pastor@upc.edu, eulalia.planas@upc.edu \\ ${ }^{b}$ Department of Mechanical Engineering, Imperial College London, SW72AZ, London, UK. \\ g.rein@imperial.ac.uk
}

\begin{abstract}
A key factor in decision-making process during a wildfire incident is counting on the forecast of how the fire is likely to behave in different fuels, weather conditions and terrain. Wildfire models and simulators attempt to assist fire responders in gaining understanding of the fire behaviour. The main hurdle to overcome when applying such technologies at operational level is the lack of a complete model that describes wildfire governing physics and the trade-off between accuracy and computing time. A forecasting prediction must be delivered within a positive lead time and current physical models are far beyond this requirement.

Inverse modelling and data assimilation techniques offer a great potential of operational applicability in wildfires, coupling fire monitoring and fire behaviour forecast at real time. With this approach, a better description of the processes simulated by the fire behaviour models can be achieved when adding real-state information of the system, since discrepancies between simulated fire behaviour variables and observed variables are minimized. The use of this approach accelerates fire simulations without loss of forecast accuracy. In this paper we explore the adaptation to real fire scenarios of a synthetic-data-based inverse modelling structure for fire behaviour forecast. Improvements are investigated to extrapolate the already existing algorithm to real data assimilation from IR aerial monitoring. The technique explores elliptical Huygens expansion coupled with simple -yet effective- semi-empirical wildfire models. The algorithm assimilates fire fronts positions extracted from airborne thermal imaging and additional available data as wind speed and direction or fuel characteristics. The invariants -set of governing parameters that are mutually independent and constant for a significant amount of time- are resolved by means of forward model and linear tangent minimization.

The technique has been adapted to be employed in large-scale mallee-heath shrubland fires experiments conducted in South Australia in 2008. Fires were filmed with a helicopter transported TIR camera. The IR images were processed to obtain the position of the fire perimeter at a maximum frequency of one isochrone every 10 seconds. The algorithm shows great capability to simulate fire fronts observations and opens the door to keep developing a fully automatic data assimilation algorithm with forecasting capacity.
\end{abstract}

Keywords: inverse modelling, data assimilation, infrared imagery, shrubland fire behaviour.

\section{Introduction}

Fire managers need to obtain real-time information as fast as possible in order to make quick potentially impactful decisions. They have to keep track of fire behaviour and suppression activities at all times with the responsibility of safeguarding physical integrity of all the individuals involved in the emergency. In response to this need, numerous activities have been recently under way to take advantage of new opportunities and technology for wildland fire management. Over the past few years several public wildfire agencies have been benefiting from different information technology tools that allow monitoring fire activity and fire brigades. A good example of such advances is the implementation of airborne fire monitoring apparatuses combined with global geo-positioning systems so that both fire and suppression resources can be tracked. With these systems, images of any interesting spot of the fire scenario can be obtained in the infrared (IR) and visible spectrum and 
transferred in real-time to the commander work station of the fire incident, so that fire managers can have more readily available information for decision-making. However, the use of this systems is currently less cost-effective than it could, not only because of the specificity of all the compounds and the costs associated to the airborne platform (e.g. surveillance helicopters and aircrafts) but also because the information they provide is not exploited quantitatively, particularly, for forecasting purposes.

A key factor in decision-making process during a wildfire incident is counting on the forecast of how the fire is likely to behave in different fuels, weather conditions and terrain. Wildfire models and simulators attempt to assist fire responders in gaining understanding of the fire behaviour. The main hurdle to overcome when applying such technologies at operational level is the lack of a complete model that describes wildfire governing physics (Finney et al., 2013) and the trade-off between accuracy and computing time. A forecasting prediction must be delivered within a positive lead time (time ahead of the predicted event) and current physical models are far beyond this requirement. Inverse modelling and data assimilation techniques offer a great potential for operational applicability in wildfires, coupling fire monitoring and fire behaviour forecast at real time. With this approach, a better description of the processes simulated by the fire behaviour models can be achieved when adding real-state information of the system, since discrepancies between simulated fire behaviour variables and observed variables are minimized. The use of this approach accelerates fire simulations without loss of forecast accuracy (Mandel et al., 2008), (Jahn et al., 2011), (Rochoux et al., 2012).

In this paper we explore the adaptation of a synthetic data assimilation-based forecasting algorithm to deal with large scale real sensed data. The algorithm to be adapted is based on the identification of some invariants (model components that are constant for a given period of time and area, such as fuel depth, moisture content, packing ratio, etc.) that are determined through an optimization process during a given assimilating window. This technique has shown great performance when challenged with synthetic data (Rios, Jahn, \& Rein, 2014) but its adaptation to a real case scenarios will require special attention. The real data that will be used are fire fronts isochrones obtained by airborne infrared imaging in mallee-heath shrublands experimental burns conducted in South Australia in 2008 (Cruz, McCaw, Anderson, \& Gould, 2013; Pérez, Pastor, Planas, Plucinski, \& Gould, 2011).

\section{Data assimilation and inverse modelling}

Data assimilation has been historically developed and applied in the weather forecasting discipline to combine observations with the models and improve forecasts with available sensed data (Kalnay, 2003). One of the most common strategies used to merge assimilated data with the model is by means of inverse modelling.

Inverse modelling is particularly appropriate for wildfires modelling due to large amount of unknowns in terms of environmental parameters, such as fuel physical properties (e.g. fuel elements distribution and thermal characteristics), weather inputs (e.g. wind profile, ambient temperature gradient and relative humidity) and terrain features (e.g. slope and aspect variability). There are numerous necessary variables to initialise a physical classical forecasting model and hardly ever can all be measured. By contrast, the inverse approach can use any kind of available data to improve the forecast if the forward model is tweaked accordingly.

Despite its great capacity for coping with complex problems with a large number of variables, still few authors have tried to apply it to the fire field. Among these, Jahn et al. (Jahn, Rein, and Torero 2011, Jahn, Rein, and Torero 2012) successfully pioneered this approach to forecast fires in enclosures using both simple and complex models (two zones models and Computer Fluid Dynamics, CFD models). In the field of wildfires, Mandel et al. (Mandel, Beezley, Coen, \& Kim, 2009) explored this technique to predict time-temperature curve of a sensor placed in the way of an advancing fire. They examined a reaction-diffusion equation and a semi-empirical fire line propagation model coupled with an 
Eulerian level-set-based equation. Additionally, they coupled weather forecast information to the model demonstrating the powerful potential of data assimilation. Despite its potential, their implementation was found to be unstable due to the ill-definition of temperature measurements in a wildfire.

Following this work, Rochoux et al. (Rochoux, Delmotte, Cuenot, Ricci, \& Trouvé, 2012b), (Rochoux, Emery, Ricci, Cuenot, \& Trouvé, 2014) developed a data assimilation algorithm using ensemble Kalman filters and a state estimation approach. The forward model (named "Firefly") was composed of a Rothermel based propagation equation for rate of spread (RoS) and a level set approach to propagate the front. The algorithm was tested with synthetically generated data and with a controlled small scale $(4 \mathrm{x} 4 \mathrm{~m})$ grassland experiment with spatially-varying fuel depth and temporally-varying wind speed and direction. One of the main drawbacks of the algorithm lies in the fact that the model deals with errors using Kalman Filters which implies the assumption that the errors are normally distributed. However, in fire, errors do not follow a Gaussian distribution (Johns \& Mandel, 2008). Nevertheless, the approach reinforces the potential of data assimilation in wildfire forecasting.

\subsection{Simple synthetic validation}

As has been mentioned, the work at hand is the improvement an adaptation to a real data context of a forecasting algorithm developed by Rios et al. (Rios et al., 2014). The algorithm is based on Huygens light propagation principle applied to wildfires propagation (Richards, 1990), (Richards, 1993) together with Rothermel model (Rothermel, 1972) to compute RoS. The Huygens principle assumes that each node in the front acts as a new elliptical propagation ignition point. Each ellipse -firelet- has the main axis directed towards the wind-slope vector (assumed to be the main propagation direction) and the magnitude of its axis is defined by equations [1-3] (Figure 1). The curve that envelopes all the firelets is then the new fire front (Figure 2).

$$
\begin{gathered}
a(s, t)=\operatorname{RoS}(s, t) \cdot \frac{1+\left(L B-\sqrt{L B^{2}-1}\right)^{2}}{2 \cdot L B} \\
b(s, t)=\operatorname{RoS}(s, t) \cdot \frac{1+\left(L B-\sqrt{L B^{2}-1}\right)^{2}}{2} \\
c(s, t)=b(s, t)-\frac{\operatorname{RoS}(s, t)}{\left(L B+\sqrt{L B^{2}-1}\right)^{2}}
\end{gathered}
$$

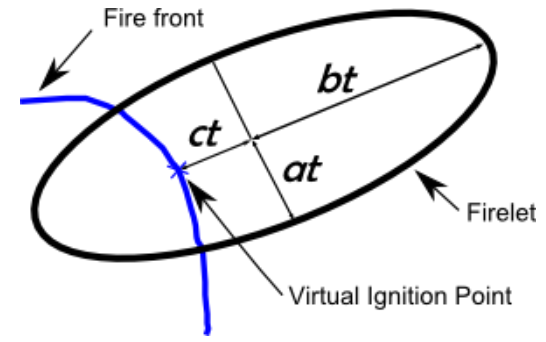

Figure 1:Firelet axis geometry

Where $L B$ is the length-to-breadth ratio and is defined by Anderson et al. (Anderson, Catchpole, De Mestre, \& Parkes, 1982) throughout an experimental correlation with the wind-slope vector and $s$ is the front parameterization variable. 


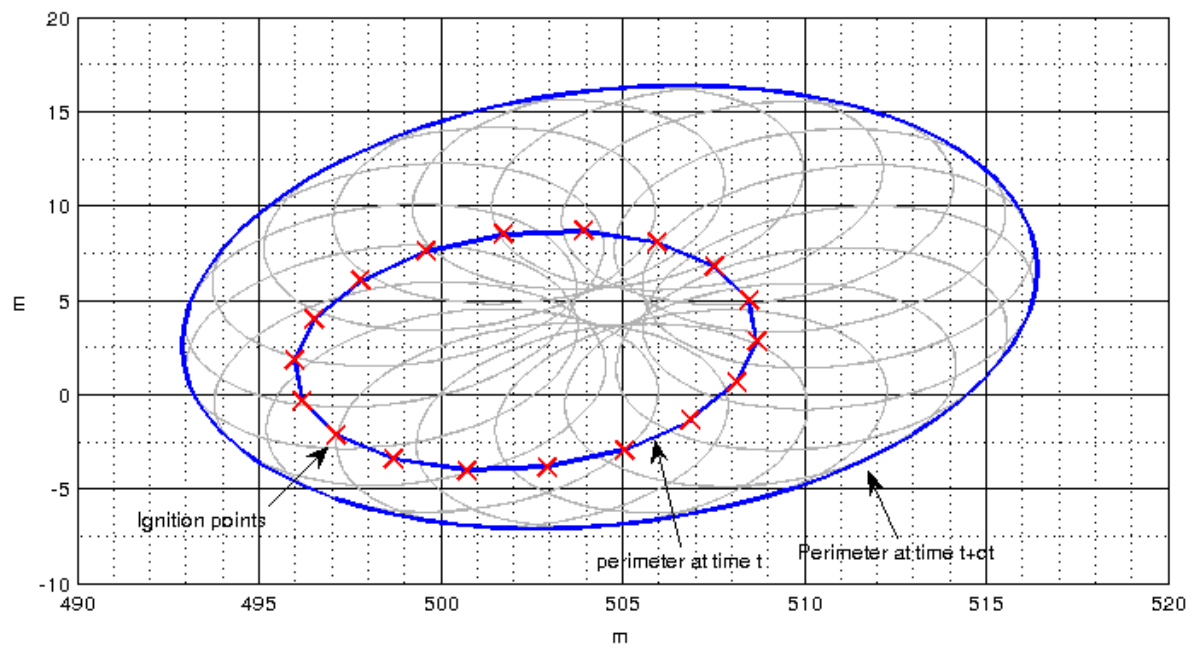

Figure 2. Illustration of the Huygens' Principle applied to fire spread. The fire front at time tis discretized into vertices (red crosses). Each of this vertex become the point source for local elliptical expansions (firelets). The curve that envelopes all the firelets is the new fire perimeter at time $t+d t$.

The optimization problem to find the invariants that best reproduce the assimilated fire fronts used a Tangent Lineal Model approach and an automatic differentiation of the forward model. To check the performance of the algorithm, different configurations of invariants were checked. In some cases, up to 4 invariants were estimated during the optimization loop and non-homogeneous fuel distribution together with temporally-varying wind direction and speed were used to recreate more real scenarios. The algorithm showed good capacity to identify the correct invariants and reproduce the assimilated fronts even when the first guested invariants value was $150 \%$ off the true value (see Figure 3 ). The computational process was fast and large lead times were achieved.

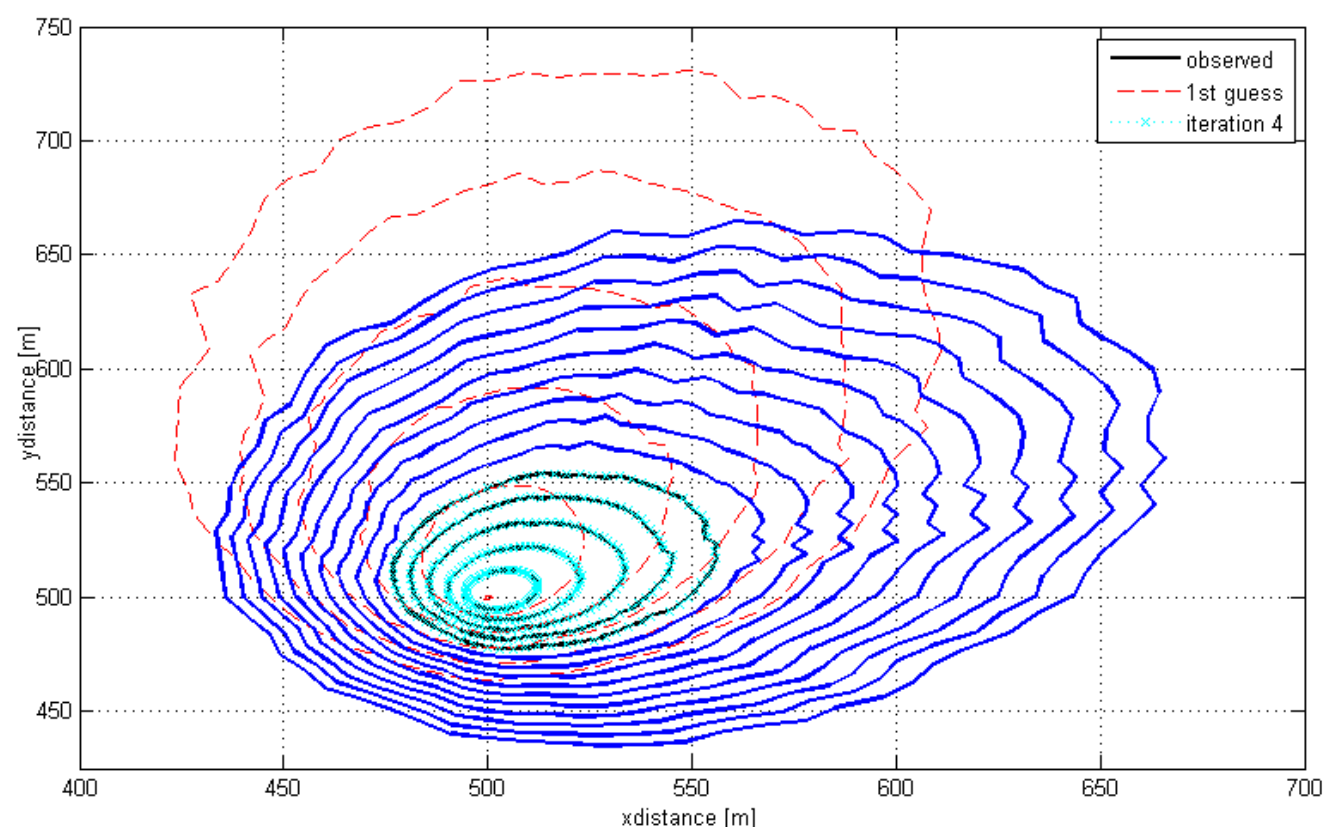

Figure 3. Fire front convergence(dotted light blue lines) towards observed data (solid black line) after 4 iterations (after Rios et al., 2014)

The complete flow diagram of the algorithm is presented inFigure 4. A first invariant's vector guess is needed to create the first forward model run. Together with the available assimilated fronts, the optimization loop identifies the most suitable invariants by means of automatic differentiation. When 
a certain convergence is achieved the invariants are assumed to be properly estimated and a forecast can be delivered. This forecast will be valid as long as the invariants remain constant.

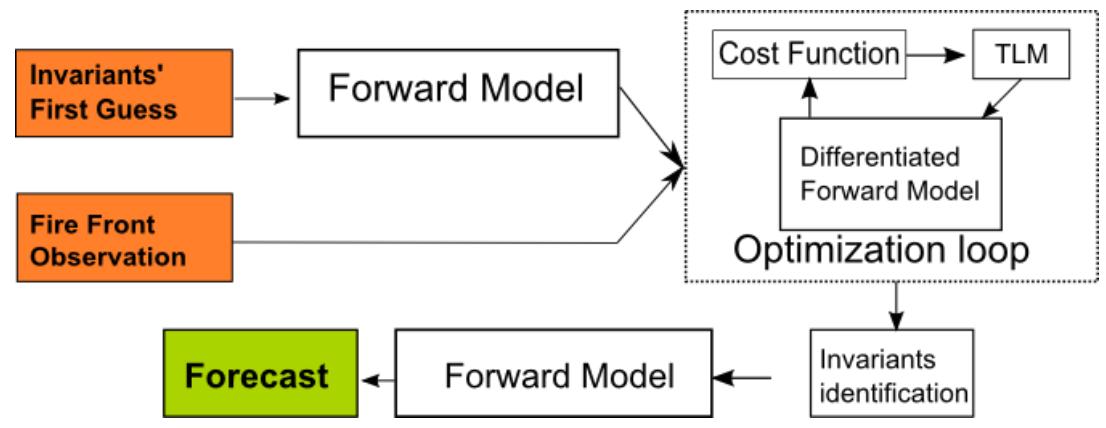

Figure 4: Diagram flow of the data assimilation algorithm. Orange boxes are input data whereas green box is the output of the algorithm.

\subsection{Real data pitfalls}

The use of real data to check the performance of the model rises some mathematical and computing problems that need to be addressed. First of all, a real fire front hardly is a closed curve, which is, however, one of the bases of the already existent algorithm (see Figure 3). There are many circumstances that may disable the fire to expand in all directions, e.g. line vs point ignition, perimeter interception by a firebreak, suppression activities, etc. Thus, the existing forward model has to be adapted to this reality and hence handle open ignition curves. For this reason, a new set of forward model differential equations needs to be implemented and integrated. Moreover, the simulated fire needs to stop on firebreaks (natural or suppression-made) or overtake them if they are inefficient. At this stage of our algorithm, when a simulated fire overtakes little fire breaks or vegetation has a great local change, the front creates sharp areas (see Figure 5) that have to be smoothed, hence improvements in terms of regridding and adding extra nodes on the perimeter have to be done. Due to this overtaking, the current code simulates front fingers that will overlap as fire propagates and recovers a convex shape (Figure 5), and because of that a filtering algorithm that correct this non-physical situations will need to be coupled to the model.

Regarding the assimilated data, in real scenarios data income concerning environmental parameters can be highly variable so the algorithm needs to be prepared to integrate data that are not regularly supplied on time and space.

Beyond the inherent algorithm difficulties, the use of the inverse modelling framework with real data also requires some additional remarks. While the assumption of the existence of some invariants parameters may remain correct for certain scenarios and time periods, it might not be such an invariant magnitude in the model that can reproduce the assimilated data, due to model simplicity. Therefore the forward model needs to be kept flexible enough to allow large adjustments and complex behaviours and front shapes. Similarly, the cost function optimization target value should not be kept too small since perfect convergence (i.e. perfect matching of simulated and observed fronts) might be impossible. Even in the cases where it converges close to zero, the correct invariant's value will not be known, and therefore the individual invariant convergence cannot be analysed as it was done in the synthetic data case.

\section{Real case algorithm adaptation}

In order to use our existing inverse modelling data assimilation structure with real sensed data some adaptation algorithms had to be implemented. This included new integration of the Huygen's expansion differential equations, a regridding algorithm, a loop clipping algorithm and a degridding algorithm. 


\subsection{Forward model equations}

The previously implemented forward model equations did not allow the initial fire perimeters to be opened curves. Thus we implemented the integration of the differential equations originally developed by Richards (Richards, 1990) for the firelets enveloping curve defined by $x$ and $y$ coordinates:

$$
\begin{gathered}
\frac{\partial x(s, t)}{\partial t}=\frac{a^{2} \cos \theta\left(\frac{\partial x}{\partial s} \sin \theta+\frac{\partial y}{\partial s} \cos \theta\right)-b^{2} \sin \theta\left(\frac{\partial x}{\partial s} \cos \theta-\frac{\partial y}{\partial s} \sin \theta\right)}{\sqrt{\left(b^{2}\left(\frac{\partial x}{\partial s} \cos \theta-\frac{\partial y}{\partial s} \sin \theta\right)\right)^{2}+\left(a^{2}\left(\frac{\partial x}{\partial s} \sin \theta+\frac{\partial y}{\partial s} \cos \theta\right)\right)^{2}}+c \sin \theta} \\
\frac{\partial y(s, t)}{\partial t}=\frac{-a^{2} \sin \theta\left(\frac{\partial x}{\partial s} \sin \theta+\frac{\partial y}{\partial s} \cos \theta\right)-b^{2} \cos \theta\left(\frac{\partial x}{\partial s} \cos \theta-\frac{\partial y}{\partial s} \sin \theta\right)}{\sqrt{\left(b^{2}\left(\frac{\partial x}{\partial s} \cos \theta-\frac{\partial y}{\partial s} \sin \theta\right)\right)^{2}+\left(a^{2}\left(\frac{\partial x}{\partial s} \sin \theta+\frac{\partial y}{\partial s} \cos \theta\right)\right)^{2}}+c \cos \theta}
\end{gathered}
$$

Where $a, b$ and $c$ are the firelet axis calculated with equations [1-3], $\theta$ is the wind-slope vector direction and $s$ the curve parameterization parameter. These equations were numerically integrated using a Prediction-Corrector method based on central difference approximation.

\subsection{Complementary algorithms}

\subsubsection{Regridding algorithm}

As mentioned in section 2.2 a regridding algorithm was needed in order to avoid sharp zones formations due to firebreaks or rapid local fuel changes. The algorithm implemented, successively analyses the angles between three correlative segments. Then, if any of the two adjacent angles is larger than a given threshold a new node is inserted in the corresponding segment and the process is repeated until all the angles meet the condition. The effect of this step can be observed in Figure 5 (before applying the algorithm) and Figure 6 (after using it). In this case, the implemented open curve differential equations are used to propagate the front.

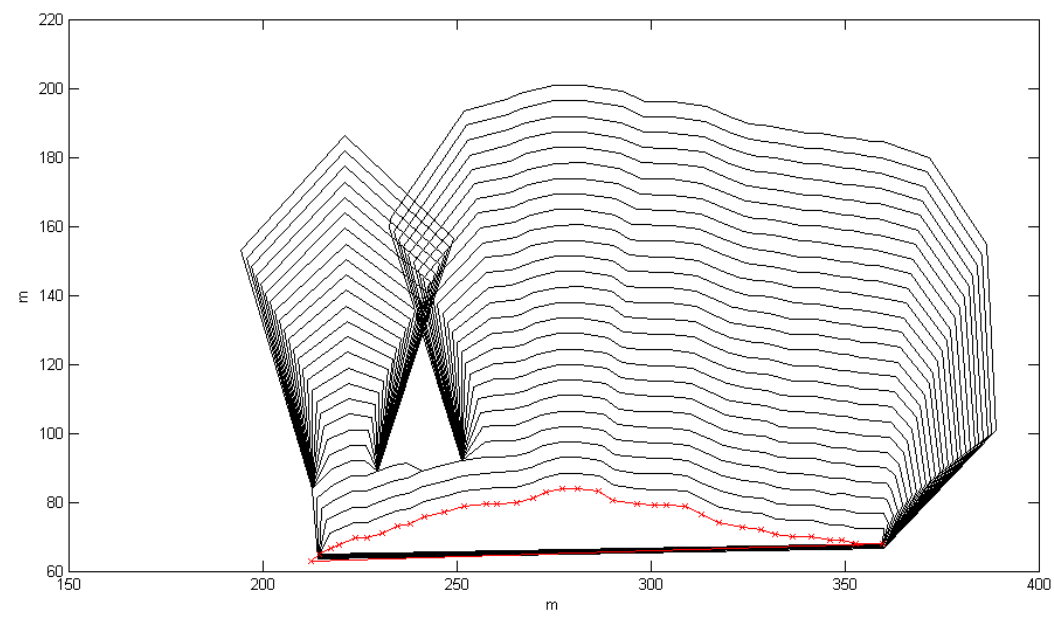

Figure 5. Propagation model showing pitfalls due to the presence of a firebreak (a rectangular 20x10m fire break is placed at coordinates [230, 90]). Line ignition (red crossed line), is taken from real fire data (shrubland experiments in South Australia 2008) 


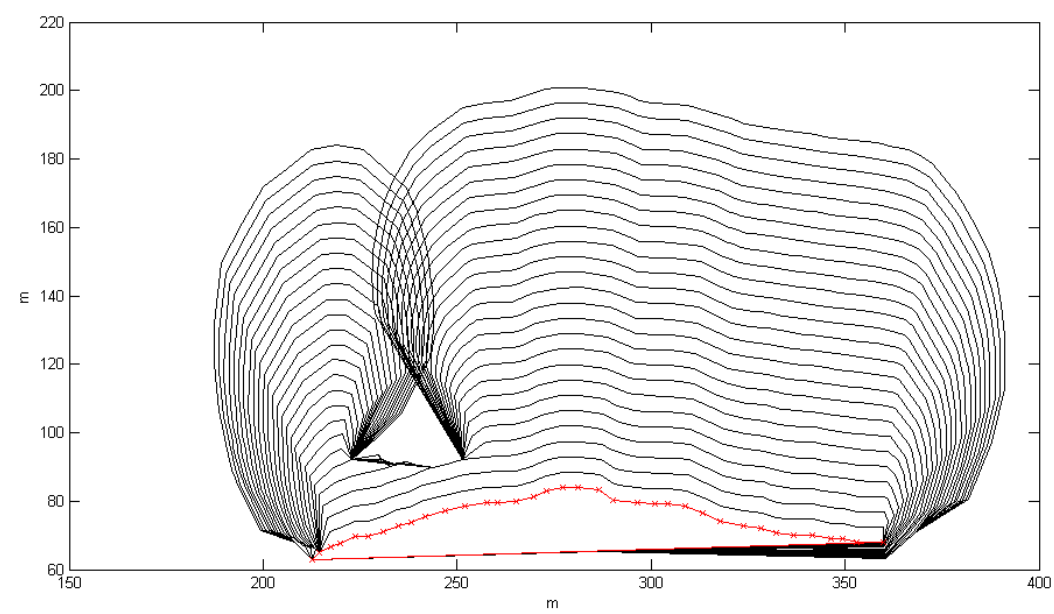

Figure 6. Effect of the regridding algorithm for the same front propagation around a firebreak as figure 5 for a threshold value of $\pi / 4$ radians.

\subsubsection{Loop-clipping algorithm}

When the front became a convex curve and kept propagating, after overtaking a fire break or due to a local fire spread acceleration, our code created overlapping loops between two front fingers or even self-crossing loops. A loop-clipping algorithm was then implemented to avoid meaningless propagations such as fire propagating inwards in a self-crossing loop. The algorithm checks for intersections at any segment and identifies the section that has to be directly removed from the propagating front. Loop clipping can create sharp curves on the loop's intersection and therefore the regridding algorithm is again called afterwards.

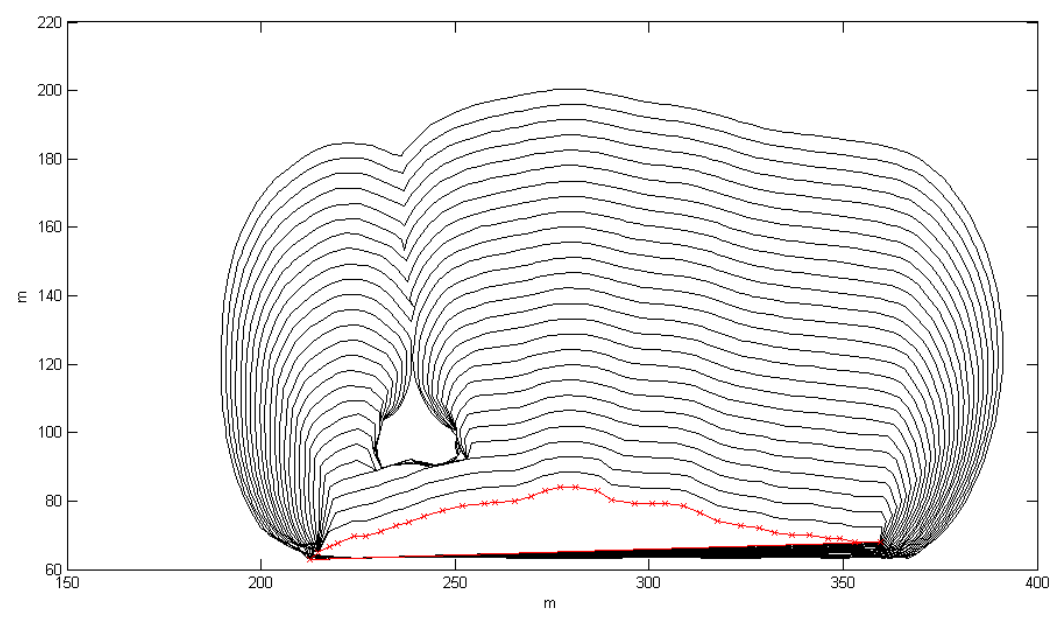

Figure 7. Effect of the loop clipping algorithm when applied to the same propagating case as Figure 6.

\subsubsection{Degridding algorithm}

After applying the mentioned improvements, as the forward model generated fire fronts and the loop clipping and regridding algorithms were run when needed, unnecessary nodes appeared in a noncurved region. To maintain performance and coherence a degridding algorithm had to be implemented. The algorithm looks for segments that are shorter than a given length (taken to be a multiple of the 
spatial sensibility) and checks that the adjacent angle is smaller than this of regrinding algorithms. If both conditions are met, the node is removed from the front (Figure 8).
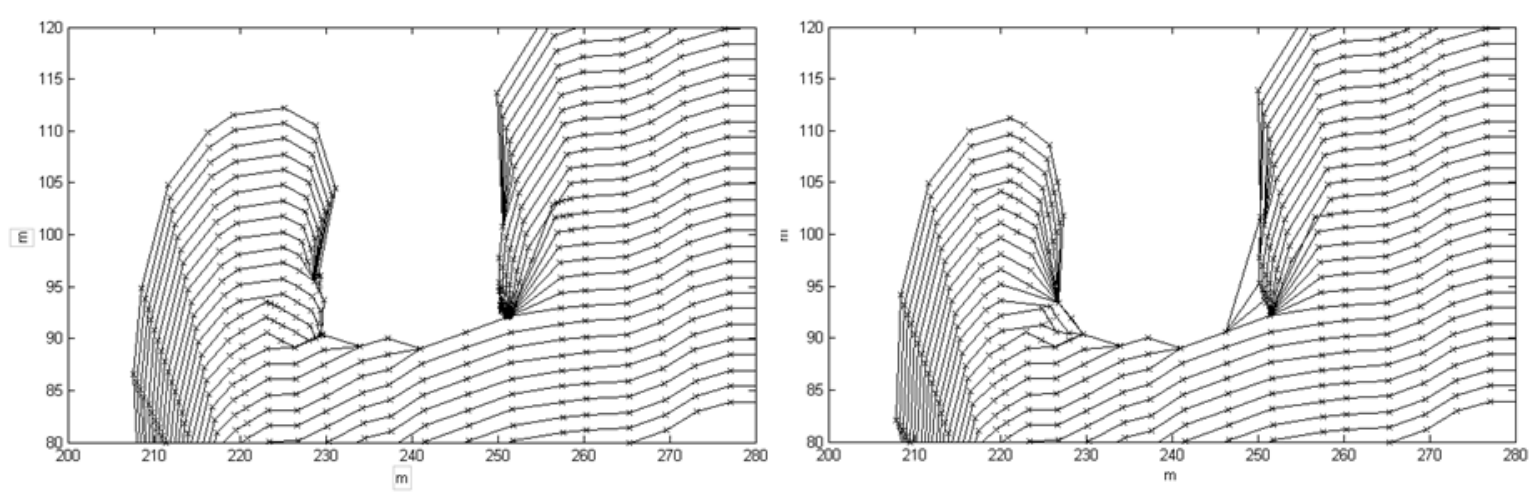

Figure 8. Around fire brake zones, the propagation algorithm creates regions of high and unnecessary node density (left figure). When the degridding algorithm is applied (right figure) those regions are reduced and the forward model can be run faster.

\subsection{Inverse modelling}

In our inverse modelling-data assimilation structure, a cost function that accounts for the discrepancies between modelled and sensed fire fronts has to be evaluated in each forward model run to determine the invariants. The best set of invariants are calculated by minimising this cost function. The cost function plays a central role in the algorithm. It has to be simple enough so its evaluation is not computationally expensive while it has to be accurate and drive the algorithm towards a meaningful convergence.

\subsubsection{Cost Function}

The cost function implemented in the previous algorithm used an angular discretization scheme to select the points on both, the model and the observed fronts. The summed up distance between each angularly related pair of points was then computed as the cost function value:

$$
J(p)=\sum_{t=t_{i}}^{t_{f}} \sqrt{\left[\overline{y_{l}}-y_{i}(p)\right]^{T} W\left[\overline{y_{l}}-y_{i}(p)\right]}
$$

Where $\bar{y}_{l}$ and $y_{i}$ are the observed and modelled front coordinates respectively, $p$ is a given set of invariants value and $W$ is a weight diagonal matrix that can be used to give more value to certain observations depending on their reliability and accuracy. In each cost function evaluation, all the available fronts are computed and summed up.

In the real data scenario the angular discretization is no longer valid due to the complex shapes. Thus, the cost function was modified by finding the Euclidian norm of a vector that connects each modelled segment mid-point with its correspondent assimilated front following the local propagation direction (perpendicular to the local curve slope). Since this distance is quantified for every assimilated fire front and the number of segments are not kept constant in each front as the perimeter expands, the total distance between each pair of isochrones is divided by the number of vectors. Figure 9 illustrates the Euclidian norm evaluation for four fire fronts assimilation. Note that some intersection vectors diverge due to the local geometry of the modelled front. In this cases, a filter is applied so vectors that are larger than the mean value plus/minus 2 times the standard deviation are removed. As both perimeters converge, the intersection vectors behaviour improves. 


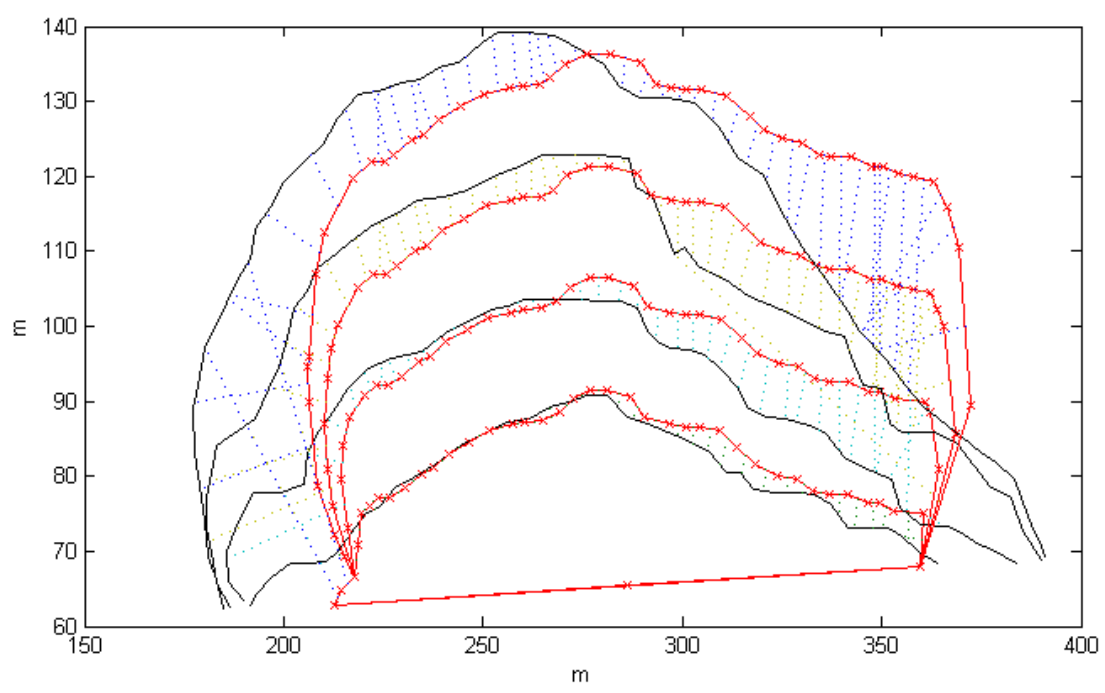

Figure 9. Paired isochrones of assimilated (black solid lines) and modelled (red dotted lines) fire fronts (real fire data from South Australia experiments 2008). The cost function is calculated by averaging the Euclidian norm of the lines perpendicular to the modelled front that intersect the corresponding observed perimeter.

\subsubsection{Tangent Lineal Model}

The optimization loop is the most critical part of the algorithm since it will affect the total computing time (and therefore compromise the lead time). The two main approaches to optimize the cost function are gradient-free and gradient-based algorithms. While the first group sweeps all the available domain and identifies absolute minimums, their algorithms are also more computationally expensive. The gradient-based algorithms assume an initial guess for the estimating parameters and use the gradient to drive the solution towards a minimum. They are particularly suitable for systems where variables are limited within a range of values. Using the later, and using a Tangent Linear Model local approximation for the forward model (based on Taylor's expansion series on the vicinity of the initial guess) the optimization step can be reduced to a linear system of equations that can be easily solved by using a QR factorization with column pivoting (Nocedal \& Wright, 1999):

$$
\sum_{t=t_{i}}^{t_{f}} H_{i}^{T} H_{i} \bar{p}=\sum_{t=t_{i}}^{t_{f}} H_{i}^{T}\left(\bar{y}-y_{i}(p)\right)
$$

Where $\bar{p}$ is the difference between an old and an updated invariant's vector, $\left(\bar{y}-y_{i}(p)\right)$ is the discrepancy between the observed and the modelled fronts and the term $H_{i}^{T} H_{i}$ is the Jacobian of the forward model. The most common numerical algorithm to calculate this term need to evaluate the forward model itself multiple times (a centred difference approach for example) which may dramatically increase the computational time. Alternatively, an automatic differentiation approach can be used to directly evaluate this term. This approach uses the chain-rule for derivatives to systematically derive the scripted code. Once this is done, the Jacobian term can be calculated with one run. If the process is repeated in a loop, the final invariant's vector is obtained when the term that contains the difference between the observations and the model converge. This algorithm is not yet implemented for the real data assimilation case due to the changes in the forward model equations. The automatic differentiation process has to include the correcting algorithms, and therefore is not straightforward. Moreover, since the complexity of the model increases, the adjoint model instead of the forward model is needed. 


\section{Model testing with real fire data}

The improvements implemented so far in our inverse modelling - data assimilation structure were tested using real fire data coming from experimental fires performed in eastern South Australia in March 2008. Despite being within a framework of a scientific experimental burning program, fires exhibited real behaviour patterns as were performed in extremely severe weather conditions and plots dimensions were all above 6 ha. These experiments were conducted in Ngarkat Conservation Park $\left(35^{\circ} 45^{\prime} \mathrm{S}, 140^{\circ} 51^{\prime} \mathrm{E}\right)$ which is constituted by a characteristic dune and swale system comprising large flat areas of mallee-heath shrublands (130 m a.s.1.). Fire behaviour in mallee-heath fuel types is characterized as being discontinuous and highly variable due to the heterogeneous characteristics of the various fuel layers that comprise mallee-heath fuel complexes (Cruz et al., 2013). Data used in this paper comes from the experimental burn performed in a 9 ha 8 year-old heath plot in March $4^{\text {th }} 2008$. This fuel complex was characterized by scattered small-leafed shrubs, organized in clumps, and a discontinuous litter layer partially buried by sand. The main fire carrying fuel layer was the discontinuous shrub canopy $\left(1.5 \mathrm{~m}\right.$ depth). Ambient conditions were temperature of $32{ }^{\circ} \mathrm{C}$ and relative humidity of $25 \%$. Wind speed ( 10 -m open) averaged $15 \mathrm{~km} / \mathrm{h}$, with gusts up to $30 \mathrm{~km} / \mathrm{h}$. Wind direction was from south-south-westerly. Characteristic dead fuel moisture of the fuel complex was $7.7 \%$. The fire was ignited with a 130-150 m long line and two minutes after ignition, flame heights were about 2-2.5 meters, with flashes up to 4 meters. The fire spread vigorously throughout the plot with sustained flames heights of 4-5 meters. Eight minutes after ignition, the main flame front hit the northern border of the plot, concluding a $350 \mathrm{~m}$ head fire run (Planas, Pastor, Cubells, Cruz, \& Grenfell, 2011) The fire was filmed from an helicopter with a IR camera (AGEMA Thermovision 570-Pro, FSI-FLIR Systems). This camera operated within the 7.5-13 $\mu \mathrm{m}$ range and was equipped with a frame grabber to control and store sequences of IR images $(240 \times 320$ pixel $)$ onto a laptop computer at an approximate rate of 5 frames per second. The helicopter was hovering positioned so that the majority of the plot was in view for the duration of each fire, allowing fire behaviour to be recorded and monitored. Isochrones map ( 1 every 10 seconds frequency) and RoS map of this fire experiment were subsequently obtained applying a methodology for IR analysis developed with MATLAB ${ }^{\circledR}$ computing software and described elsewhere (Pastor et al., 2010).

Using the first observed perimeter as an ignition line, the forward model was run fed with the moisture content, wind speed and direction and fuel load and depth values. Figure 10 shows the comparison between $5 \mathrm{~min}$ of real burning fronts, sampled every $10 \mathrm{sec}$. and the modelled isochrones for the same period of time. While individual isochrones shape do not perfectly match all the observed fronts, the total distance travelled by the head fire is well predicted. Similarly, the left flank of the fire is properly predicted as time passes by. Taking into account that the plot had a high fuel discontinuity not added to the model, and also that the wind variation was neither considered, the simulations are reasonably accurate and support the need for and the suitability of an automatic data assimilation algorithm capable of identifying this factors difficult to obtain with enough accuracy during operational scenarios.

\section{Conclusions}

The required steps to adapt a data assimilating system to work with real sensed data have been investigated and implemented in a wind-driven short-term forecasting algorithm. Difficulties such as front concavity, fire breaks and fuel irregularities have been identified and addressed in the forward model. The assimilating capacity of the algorithm can be now explored by casting different invariants configurations and performing the optimization step with an automatic differentiation approach to ensure positive lead time. The preliminary check with airborne thermal images of a large scale experiment showed the capacity of the implemented forward model of reproducing head fire 
propagation and overall fire growth with a reasonable accuracy and highlights the potential of an automatic assimilation algorithm implementation.

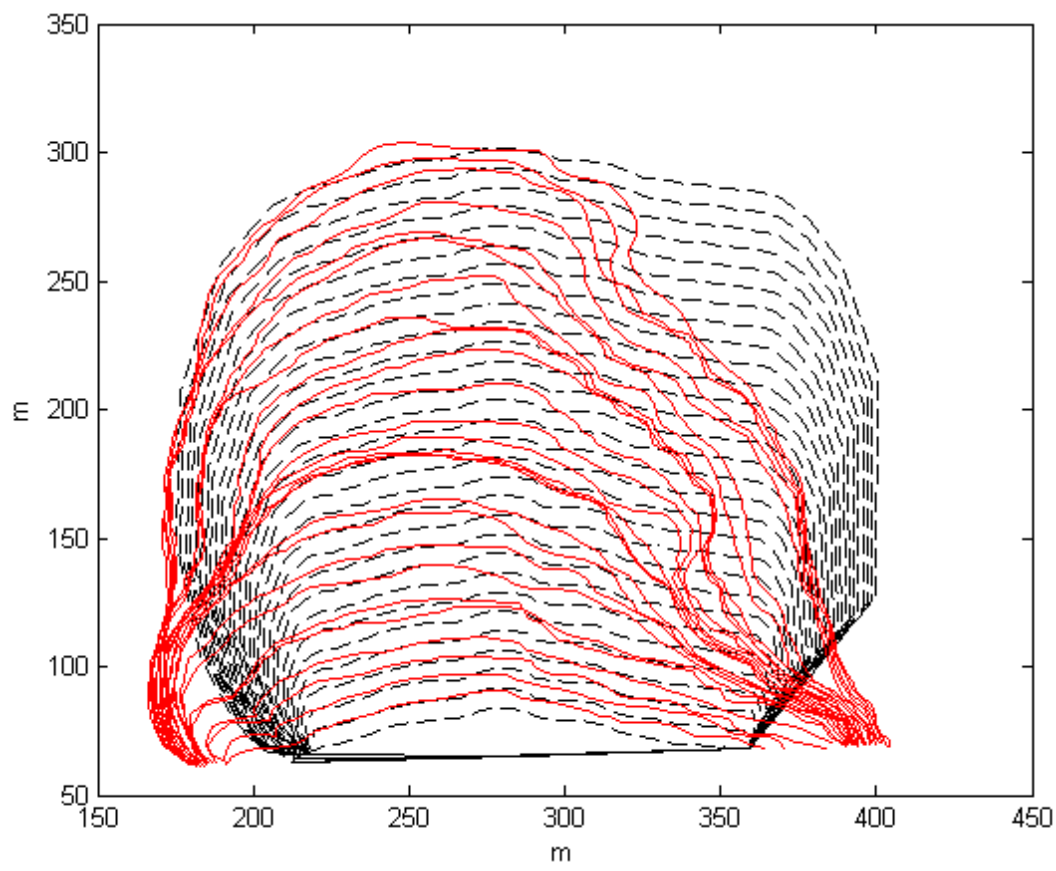

Figure 10. Modelled fronts (dashed lines) versus Ngarkat's plot " $A$ " real perimeters (solid lines). Isochrones are plotted every 10 secons during 5 min. (i.e. 30 isochrons are depicted). The fuel depth is estimated of $1.3 \mathrm{~m}$ and the wind is set to $3 \mathrm{~m} / \mathrm{s}$.

\section{Acknowledgements}

This work is supported by Agaur (FI-DGR 2014FI-00133). The authors also thank the Autonomous Government of Catalonia for financial support (project No. 2009SGR1118).

\section{References}

Anderson, D. H., Catchpole, E. A., De Mestre, N. J., \& Parkes, T. (1982). Modelling the spread of grass fires. Journal of the Australian Mathematical Society, 23, 451-466.

Cruz, M. G., McCaw, W. L., Anderson, W. R., \& Gould, J. S. (2013). Fire behaviour modelling in semi-arid mallee-heath shrublands of southern Australia. Environmental Modelling \& Software, 40, 21-34.

Finney, M., Cohen, J. D., McAllister, S. S., \& Jolly, W. M. (2013). On the need for a theory of wildland fire spread. International Journal of Wildland Fire, 22(1), 25. doi:10.1071/WF11117

Jahn, W., Rein, G., \& Torero, J. L. (2011). Forecasting fire growth using an inverse zone modelling approach. Fire Safety Journal, 46(3), 81-88.

Jahn, W., Rein, G., \& Torero, J. L. (2012). Forecasting fire dynamics using inverse computational fluid dynamics and tangent linearisation. Advances in Engineering Software, 47(1), 114-126.

Johns, C. J., \& Mandel, J. (2008). A two-stage ensemble Kalman filter for smooth data assimilation. Environmental and Ecological Statistics, 15(1), 101-110.

Kalnay, E. (2003). Atmospheric modeling, data assimilation and predictability (p. 203). UK: Cambridge University Press. 
Mandel, J., Beezley, J. D., Coen, J. L., \& Kim, M. (2009). Data assimilation for wildland fires. Control Systems, IEEE, 29(3), 47-65.

Mandel, J., Bennethum, L. S., Beezley, J. D., Coen, J. L., Douglas, C. C., Kim, M., \& Vodacek, A. (2008). A wildland fire model with data assimilation. Mathematics and Computers in Simulation, 79(3), 584-606.

Nocedal, J., \& Wright, S. J. (1999). Numerical Optimization. (J. Nocedal \& S. J. Wright, Eds.). New York: Springer-Verlag. doi:10.1007/b98874

Pastor, E., Pérez, Y., Cubells, M., Planas, E., Plucinski, M., \& Gould, J. (2010). Quantifiable assessment of aerial suppression tactics in wildland fires using airborne infrared imagery. In D. X. Viegas (Ed.), VI International Conference on Forest Fire Research (p. 15 pp.). Coimbra, Portugal.

Pérez, Y., Pastor, E., Planas, E., Plucinski, M., \& Gould, J. (2011). Computing forest fires aerial suppression effectiveness by IR monitoring. Fire Safety Journal, 46, 2-8. doi:10.1016/j.firesaf.2010.06.004

Planas, E., Pastor, E., Cubells, M., Cruz, M. G., \& Grenfell, I. C. (2011). Fire behavior variability in mallee-heath shrubland fires. In 5th International Wildland Fire Conference (p. 10 pp.). 9-13 May, 2011. Sun City, South Africa.

Richards, G. D. (1990). An elliptical growth model of forest fire fronts and its numerical solution. International Journal for Numerical Methods in Engineering, 30(6), 1163-1179.

Richards, G. D. (1993). The properties of elliptical wildfire growth for time dependent fuel and meteorological conditions. Combustion Science and Technology, 95(1-6), 357-383.

Rios, O., Jahn, W., \& Rein, G. (2014). Forecasting wind-driven wildfires using an inverse modelling approach. Natural Hazards and Earth System Science, 14(6), 1491-1503. doi:10.5194/nhess-141491-2014

Rochoux, M. C., Delmotte, B., Cuenot, B., Ricci, S., \& Trouvé, A. (2012a). Regional-scale simulations of wildland fire spread informed by real-time flame front observations. Proceedings of the Combustion Institute.

Rochoux, M. C., Emery, C., Ricci, S., Cuenot, B., \& Trouvé, A. (2014). Towards predictive simulation of wildfire spread at regional scale. In Iafss 2014. IAFSS 11 th.

Rothermel, R. C. (1972). A mathematical model for predicting fire spread in wildland fuels. Intermountain Forest \& Range Experiment Station, Forest Service, US Department of Agriculture. 